25. L. V, Lect. I, No. 3

26. L. V, Lect. II, No. 12

27. L. V, Lect. V, No. 1

28. L. V, Lect. V, No. 4

29. L. V, Lect. V, No. 6

30. L. V, Lect. V, No. 7

31. L. V, Lect. V, No. 10

32. L. V, Lect. VI, No. 3

33. L. V, Lect. VII, No. 8

34. L. V, Lect. XIII, No. 9

35. L. V, Lect. XVI, No. 6

36. L. V, Lect. XX, No. 11

37. L. V, Lect. XX, No. 11

38. L. V, Lect. XXI, No. 19

39. L. V, Lect. VI, No. 13

40. L. VII, Lect. VI, No. 33

41. L. VII, Lect. XI, No. 33

42. L. VII, Lect. XVI, No. 17

43. L. VIII, Lect. I, No. 5

\section{Hombre, mundo y lenguaje en la ontología hermenéutica de Hans-Georg Gadamer}

Francisco Fernández Labastida Pontificia Università della Santa Croce

In his masterwork, Truth and Method, Gadamer seeks to resolve the fracture between being and truth produced in Modernity by the primacy of self-consciousness and scientism. Gadamer finds in language (logos) the ultimate ground for the correspondence of finite human intellect and being, without being forced to return to the classical metaphysical assertion that held God as the foundation of the adaequatio rei et intellectus. For Gadamer, in language man and world are inseparably intertwined. As a consequence, within logos every ontological difference disappears, dissolving the being of man into the infinite historical becoming of the real protagonist: language.

\section{De la interpretación de textos a la hermenéutica filosófica}

En su acepción tradicional, el término "hermenéutica" indica cualquier actividad de interpretación, desde la traducción de una lengua a otra a la explicación e interpretación de las oscuridades o dificultades de cualquier texto, ya sea éste sagrado o profano. Sin embargo, esta noción ha sufrido cambios profundos en los dos últimos siglos. A partir del siglo diecinueve, su campo semántico se ha ido ampliando gradualmente, gracias a las reflexiones acerca del fundamento de la interpretación hechas por Friedrich Schleiermacher. Para la conciencia crítica de este teólogo romántico, no sólo los textos o discursos requieren interpretación, sino toda expresión histórica del hombre - ya sea ésta religiosa, artística o Agradezco a los Prof. Francesco Russo y Stephen L. Brock sus sugerencias y
comentarios. 
filosófica-, si se quieren comprender la intencionalidad de su autor y su significado originario.

Más tarde, Wilhelm Dilthey daba otro paso en la dirección emprendida por Schleiermacher, al hacer de la comprensión (Verstehen) la base del conocimiento de toda manifestación del espíritu humano. Dilthey define la comprensión como "el proceso mediante el cual conocemos algo psíquico a través de los signos sensibles que lo manifiestan". ' Para el teorizador del fundamento de las ciencias del espíritu (Geisteswissenschafien), "en las piedras y el mármol, en las notas musicales y en los gestos, en las palabras y la escritura, en los sistemas económicos y las constituciones, es el mismo espíritu humano el que nos habla y pide ser interpretado". ${ }^{2} \mathrm{La}$ hermenéutica o interpretación (Auslegung), en cuanto técnica o ciencia de la comprensión del espíritu humano, está llamada a cumplir esa tarea. Asi, la hermenéutica deja de ser considerada una ciencia auxiliar entre otras, y se convierte en el fundamento metodológico de las humanidades.

El horizonte de la hermenéutica se ensanchó ulteriormente en la primera mitad del siglo pasado, superando los límites de la metodología de las ciencias del hombre. La pregunta por el sentido del ser llevó a Martin Heidegger en los años veinte a esbozar la llamada "hermenéutica de la facticidad", que puso en marcha el giro ontológico de la hermenéutica. ${ }^{3}$ En las reflexiones heideggerianas, la comprensión y el lenguaje dejan de ser categorías o instrumentos gnoseológicos para convertirse en manifestaciones del modo de ser

\footnotetext{
1 Wilhelm DiLTHEY: "Die Entstehung der Hermeneutik", en Gesammelte Schriften, Leipzig-Stuttgart-Gortingen: B.G. Teubner-Vandenhoeck und Ruprecht, 1914, vol. V, p. 318.

${ }^{2}$ W. DiltheY: "Die Entstehung...”, pp. 318-319.

3 Cf. Jean GREISCH: Hermeneutik und Metaphysik. Eine Problemgeschichte, Wilhelm Fink, Manchen, 1993, pp. 177ss; y Gaspare MURA: Ermeneutica e verità. Storia e problemi della filosofia dell 'interpretazione, Roma: Città Nuova, 1990, pp. 218 ss. Aunque existe un buen número de ensayos sobre la historia de la hermenéutica, estos libros exponen la evolución filosófica de la hermenéutica desde el punto de vista de sus relaciones con la metafisica.
}

propio del hombre. ${ }^{4}$ Para Heidegger, el lenguaje es la sede en la que se "da" o manifiesta el ser. "El lenguaje es la casa del ser. En su morada habita el hombre". 5 Por lo tanto, si queremos llegar al ser, tenemos que recorrer la via del lenguaje.

En su grande obra Verdad y método (1960), Hans-Georg Gadamer ordenó y completó las intuiciones de Heidegger, dando vida a una línea de pensamiento que ha sido llamada por algunos ontología hermenéutica. En este nuevo avatar, la hermenéutica ya no es una ciencia auxiliar de la filosofía, de la teología o de la jurisprudencia, sino que supera las fronteras de la crítica textual: la intención de Gadamer en Verdad y Método es, sobre todo, filosófica. No busca dar orientaciones generales para la acción interpretativa, sino más bien comprender "lo que ocurre con nosotros por encima de nuestro querer y hacer". ${ }^{6}$ Para esto, Gadamer se propone "rastrear y mostrar lo que es común a toda manera de comprender".? Por una parte, intenta aclarar cómo lleva a cabo el hombre la comprensión de si mismo y de su mundo a través del lenguaje, y por otra desentrañar el problema del logos (la palabra, pero con toda la carga conceptual que tiene el término griego) como fundamento de la verdad. Así, a la vuelta de dos siglos, esta evolución de la hermenéutica en ontología pretende ocupar el vacío dejado por la metafísica clásica en cuanto
philosophia prima.

Las páginas de Verdad y método encierran una reflexión ontológica acerca del lenguaje como fundamento último del ser. En efecto, en el centro de gravedad de la hermenéutica filosófica gadameriana no se encuentra al hombre, sino el logos. Esta obra se enmarca dentro de la reacción post-hegeliana de crítica del primado que la autoconciencia del sujeto cognoscente ha ejercido en la filosofía desde el inicio de la Modernidad. Su autor busca

\footnotetext{
${ }^{4}$ Cf. Jean Grondin: "Gadamer's Understanding of Understanding", en Robert J. DOSTAL (ed.): The Cambridge Companion to Gadamer, Cambridge: Cambridge 5 University Press, 2002, p. 36.

Mrankfin HEIDEGGER: "Brief uber den 'Humanismus"', en Gesamtausgabe, Frankfurt am Main: Vittorio Klostermann, 1976, vol. 9, p. 313

${ }^{6}$ Hans-Georg Gadamer: Verdad y Método, Salamanca: Sigueme, 1977, p. 10. ahora en adelante, al citar Verdad y método utilizaremos la sigla VM.
${ }^{7}$ VM, p. 13 .
}

(1)


positivamente privar al sujeto - es decir, al yo humano- de la preeminencia que había usurpado en la gnoseología de los últimos cuatro siglos, redimensionándolo e insertándolo en un contexto más amplio. Con esta operación, Gadamer quiere colocar al hombre como ser finito y temporal- de nuevo en su lugar, para que de esta manera lo humano recupere sus facciones originarias, deformadas por el subjetivismo moderno. Sin embargo, aunque entre sus abundantes escritos no haya ningún tratado sistemático acerca del hombre, éste se encuentra presente siempre -implícita o explícitamente- en todas sus reflexiones.

En la obra de Hans-Georg Gadamer se entrelazan el pensamiento clásico y las reflexiones de la modernidad: Platón, Aristóteles, Kant, Hegel y Heidegger. Su peculiar visión de la hermenéutica recupera la tradición y las auctoritates como elementos positivos en el proceso de comprensión e interpretación de lo humano, poniendo un límite a la actitud crítica del racionalismo ilustrado. Jürgen Habermas señala como su característica dominante el esfuerzo continuo por "establecer puentes": 8 no sólo entre las personas, sino también entre las diferentes tradiciones culturales y de pensamiento. Gadamer era un gran conversador, hombre de diálogo y de debate: le gustaba plantear problemas a sus interlocutores y responder a sus preguntas, pues le daban la ocasión de intercambiar ideas, pero sin imponerse, con un total respeto de las opiniones de sus interlocutores. ${ }^{9}$ No se puede esperar menos de un estudioso de la dialéctica clásica y fino intérprete de la obra de Platón.

8 Jürgen HABERMAS: "Urbanizzazione della provincia heideggeriana", en $A u t-A u t$, 217-218 (1987), p. 22.

9 En el telegrama de pésame que envió al cardenal Lehmann - presidente de la Conferencia Episcopal de Alemania - con ocasión de la muerte de Gadamer (11-II1900/13-III-2002), Juan Pablo II recordaba conmovido las diversas ocasiones en las que había podido intercambiar ideas con él en los coloquios que organizaba con intelectuales. En esas breves líneas, el Papa filósofo destacaba las cualidades que había podido apreciar en "este noble humanista» durante esos encuentros veraniegos en Castelgandolfo: "la sinceridad en la búsqueda de la verdad, la agudeza del pensamiento, el cordial respeto del interlocutor, la consideración por los valores del patrimonio cristiano. En efecto, Gadamer era un partidario convencido de la importancia de la tradición para una forma adecuada de conocimiento. La referencia a la tradición constituía para él el reconocimiento de un patrimonio cultural que pertenece a toda la humanidad" (16-III-2002).
No es el objetivo de estas pocas páginas ofrecer al lector una visión panorámica de la hermenéutica filosófica de Hans-Georg Gadamer, sino solamente poner en evidencia la intrincada relación ontológica entre el hombre, el mundo y el lenguaje que la fundamenta. Sin embargo, antes de entrar en materia, y con la finalidad de encuadrar históricamente la ontología gadameriana, dedicaremos el primer apartado a una breve exposición de la problemática metafísico-gnoseológica que ésta intenta resolver.

\section{Verdad vs. método}

\subsection{La revolución del método experimental}

En los albores de la Modernidad, la invención del método experimental permitió finalmente edificar el conocimiento acerca de la naturaleza sobre una base firme. La nueva ciencia cambió lenta pero inexorablemente la visión del mundo que hasta entonces había estado vigente en la cultura occidental, gracias al trabajo de científicos, matemáticos y filósofos de la talla de Galileo, Descartes, Kepler, Pascal y Newton. Junto con ella, mutó también el lugar que el hombre ocupaba en este mundo y el modo de mirarse a sí mismo. En efecto, a medida que progresaban las ciencias experimentales, se desvanecía en la conciencia del hombre moderno la sensación de estar a merced de unas fuerzas impredecibles o incontrolables que gobiernan la naturaleza. Se abandonaron las explicaciones de los fenómenos naturales fundadas sobre causas metafísicas o teológicas, en beneficio de una explicación por medio de leyes científicas verificables empíricamente. Con gran optimismo, la humanidad se descubría capaz de explicar la legalidad de los fenómenos físicos, predecirlos y, en muchos casos, dirigirlos para su propio provecho. Así, además de ser medio para alcanzar un saber teórico, el método experimental se reveló como un formidable instrumento técnico que permitía al hombre explotar racionalmente los recursos del mundo.

La fecundidad del método científico en su aplicación al conocimiento de la naturaleza llevó a Descartes a querer fundar de clásica la filosofía, pero ahora de manera metódica, pues la filosofia clásica era incapaz de justificar sus afirmaciones ante las exigencias críticas de la ciencia moderna. El método a utilizar debía permitir 
alcanzar un conocimiento cierto e indudable acerca de la realidad. Para eso, los fundamentos de dicho saber debían ser independientes tanto del carácter contingente de la experiencia sensible como de los intereses y condicionamientos de la subjetividad individual. ${ }^{10}$

Prescindiendo de los resultados concretos que Descartes obtuvo partiendo del cogito, el espíritu que inspiraba el proyecto filosófico cartesiano ejercitó un considerable influjo en la génesis y conformación de las actuales nociones de objetividad y demostrabilidad, que se encuentran en la base de la mentalidad científica contemporánea y que cambiaron radicalmente el modo clásico de entender la verdad. Como hace notar Gadamer, "si la verdad (veritas) supone la verificabilidad — en una u otra forma-, el criterio que mide el conocimiento no es ya su verdad, sino su certeza. Por eso el auténtico ethos de la ciencia moderna es, desde que Descartes formulara la clásica regla de certeza, que ella sólo admite como satisfaciendo las condiciones de la verdad lo que satisface el ideal de certeza"." Así, al poner como condición para aceptar algo como verdadero que esto pueda ser "verificado" metódicamente, ipso facto la verdad deja de ser lo que había sido hasta entonces para la filosofia antigua y medieval: adaequatio rei et intellectus.

Otra consecuencia directa del primado que adquiere en el pensamiento moderno y contemporáneo la demostrabilidad y la certeza, es la imposibilidad de pretender que sean verdaderas las afirmaciones meta-fisicas, es decir, aquellos enunciados cuyo fundamento último se encuentra en un más allá de la experiencia sensible. Dios, el alma espiritual, la inmortalidad, la ley moral, etc., se convierten así en meras creencias o ideas cuya justificación se

${ }^{10} \mathrm{Cf}$. Gianni VatTIMO: "L'ontologia ermeneutica nella filosofia contemporanea", presentación a Hans-Georg GADAMER: Verità e metodo, Milano: Bompiani, 1983, p.
$\mathrm{V}$.

11 Hans-Georg Gadamer: "¿Qué es la verdad? (1957)” en Verdad y Método II, Salamanca: Sigueme, 1992, p. 54. De ahora en adelante, al citar esta obra utilizaremos la sigla VM-II.

Aunque el título parezca indicar que se trata de una continuación de Verdad $y$ Método, este segundo volumen es una selección de artículos y conferencias algunos de ellos publicados antes de 1960- que Gadamer presenta para completar o explicitar las ideas del primero. encuentra en la fe sobrenatural o en la simple afirmación de la voluntad.

Por otra parte, la división de la realidad en dos ámbitos contrapuestos - la res extensa (materia) y la res cogitans (espíritu) - que el mismo Descartes introdujo, se convirtió poco a poco en un auténtico dualismo gnoseológico, que opone el yo como sujeto activo del conocimiento al conjunto de los objetos que conoce y que componen el mundo. Este cambio de perspectiva supuso el inicio de una revolución en la filosofía, que culminará en el "yo pienso" kantiano como sede de la legalidad del conocimiento. Es verdad que para Kant no existe conocimiento verdadero sin el concurso de la experiencia sensible, pero su verdad depende de condiciones trascendentales (del sujeto), que son independientes tanto de dicha experiencia como del yo empírico e individual. Ahora bien, si el sujeto dicta las reglas de la verdad a la experiencia, entonces la verdad no nos viene al encuentro, es decir, no se da una "experiencia" de la verdad. Por consiguiente, el criticismo trascendental ha convertido las leyes que gobiernan la ciencia experimental en la piedra de toque que determina la verdad o falsedad del conocimiento. Análogamente, para poder tener valor universal, los principios
éticos que rigen la vida del hombre no se pueden originar en el conocimiento sensible o en la voluntad del individuo. Para Kant, la "meterminación de lo bueno se fundamenta en una legalidad "metódica" (trascendental) propia de la voluntad - los postulados categóricos de la razón práctica-, que son independientes de las categorías de la razón pura. De este modo, la Crítica de la razón práctica sanciona como definitiva e insalvable la brecha entre el deber moral y el conocimiento racional que el nominalismo había incoado y que Hume había teorizado en modo explícito. Ahora, Dios y la racionalidad divina ya no son más la fuente última y la garantía de la verdad, como era para Descartes al inicio de la Modernidad, sino sólo la condición de posibilidad de la moralidad. Así, la metafísica ha encontrado entre las ideas regulativas de la razón práctica kantiana su colocación definitiva dentro de la Modernidad. tampoco se deja constreñir por los estrechos márgenes que permite el 
conocimiento científico. Por lo tanto, Kant relegará la experiencia estética a un ámbito distinto e independiente del intelecto y de la voluntad: el sentimiento. De esta manera, la Belleza no tendrá nada que ver con la Verdad y con el Bien para la mentalidad esteticista de la Modernidad tardía y del Romantizismo.

El resultado final de la revolución científica que ha tenido lugar en el periodo moderno es, por tanto, un cuadro con luces y sombras. El conocimiento de la naturaleza dio un salto cualitativo, pero acompañado de algunos efectos perniciosos a nivel gnoseológico y antropológico. En efecto, al identificar la verdad con la certeza, el afán metódico de la filosofia y de la ciencia modernas no sólo han dejado fuera de lo que puede ser conocido como verdadero buena parte del ser y del hacer del hombre a lo largo de su historia, sino que ha causado la quiebra de la unidad interna del ser humano, dividiéndolo en tres compartimientos estancos: intelecto, voluntad y sentimiento.

\subsection{Superación del reduccionismo cientista}

Sin negar el valor y la positividad del conocimiento científico, Hans-Georg Gadamer se opone al absolutismo cientista impuesto por la filosofia moderna, porque "no todo lo que es, es o puede ser objeto de la ciencia".12 Como hemos visto, el ideal del conocimiento científico resulta un criterio reductivo de verdad si es aplicado indiscriminadamente a todos los ámbitos de la realidad humana, limitando la verdad a la verificabilidad, es decir, a la capacidad de comprobar empíricamente una afirmación o de reproducir experimentalmente un efecto. Más allá del campo de la certeza cartesiana se dan experiencias de la verdad que podemos llamar "extra-metódicas". Gadamer pone como ejemplo los casos concretos del arte y de la historia. ${ }^{13} \mathrm{La}$ experiencia de la belleza como "splendor veritatis", que fundamenta tanto la creación artística como

${ }^{12}$ Hans-Georg GadAMER: "Sobre la planificación del futuro (1966)" en VM-II, p. 168.

${ }^{13}$ Gadamer dedica la totalidad de la primera parte de Verdad y método y la primera sección de la segunda a desarrollar con gran detalle estas ideas. Si se quiere consultar una exposición sucinta del problema se puede ver Hans-Georg GADAMER "La universalidad del problema hermenéutico (1966)" en VM-II, pp. 213-224. la apreciación de la obra de arte, se empobrece grandemente al intentar sujetarla a unos "cánones" estéticos objetivos, dotados de una pretendida validez absoluta. Lo mismo ocurre con la experiencia histórica. Los hechos históricos se desnaturalizan y se hacen incomprensibles si se les aplica una metodología análoga a la de las ciencias naturaies, es decir, un método que pretenda aplicar leyes que los expliquen y predigan en modo riguroso y necesario. Este problema se presenta siempre que intentamos entender cualquier fenómeno humano, ya sea éste un documento escrito, o una conversación entre dos personas, o un evento político. El entendimiento tiene ante sí algo distinto del objeto de las ciencias de la naturaleza, y requiere por tanto un enfoque diferente. Wilhelm Dilthey insistía en esta diferencia de actitud utilizando la conocida distinción entre el explicar (Erklären) y el comprender (Verstehen): la naturaleza la "explicamos", pero las creaciones del espíritu humano las "comprendemos". ${ }^{14}$

Según Gadamer, el idealismo hegeliano intenta salvar la fragmentación de la experiencia humana, al conciliar el mundo objetivo de la naturaleza con el de la cultura humana en el seno de la subjetividad. La total auto transparencia del espíritu absoluto para si mismo comprende y reconcilia en sí la conciencia subjetiva y el espíritu objetivo de modo sistemático y racional. Sin embargo, a pesar de su afán superador, Hegel no representa una ruptura real respecto al proyecto moderno, sino más bien su expresión más extrema. La autoconciencia del espíritu absoluto - es decir, la certeza que el yo tiene de sí mismo y de la verdad de sus afirmaciones, caracterizadas por la claridad y distinción- sigue siendo para Hegel la instancia suprema, como lo ha sido para toda la Modernidad a partir de Descartes. ${ }^{15}$

Ahora bien, la absolutización de la autoconciencia no resiste la labor de "desenmascaramiento" Ilevada a cabo por los maestros de la sospecha, que sostienen que la conciencia, lejos de ser la instancia última, es sólo una estructura que se levanta ya sea sobre las condiciones de producción de los medios de subsistencia (Marx), o

\footnotetext{
$14 \mathrm{Cf}$.Wilhelm DiltheY: "Ideen über eine beschreibende und zergliedernde Psychologie" en Gesammelte Schriften ..., vol. V, p. 144

15 Cf. G. VATtimo: "L'ontologia ermeneutica...", p. II.
} 
sobre la voluntad de poder (Nietszche), o sobre las pulsiones subconscientes de la libido (Freud). Pero estos autores no logran proponer una solución razonable a la ruptura de la armonía entre el alma y el mundo provocada por el advenimiento de la Modernidad. Hasta ese momento, la metafísica había garantizado la correspondencia del intelecto con las cosas por medio de la relación trascendental entre verdad y ser, al que pertenece -0 del que se predica - la verdad (esse ut verum). Para la filosofia clásica y medieval, la verdad de las cosas reside en modo pleno sólo en el intelecto divino, que las conoce como verdaderas y las hace ser. ${ }^{16}$ Esta fundamentación metafisica hacía posible la experiencia de la verdad de las cosas respetando tanto la finitud del yo que conoce como la alteridad del mundo conocido. En efecto,

en la metafisica la pertenencia se refiere a la relación trascendental entre el ser y la verdad, que piensa el conocimiento como un momento del ser mismo, no primariamente como un comportamiento del sujeto. Esta inclusión del conocimiento en el ser es el presupuesto del pensamiento antiguo y medieval. Lo que es, es por su esencia verdad; es decir, está presente en el presente de un espiritu infinito, y sólo por esto le es posible al pensamiento humano y finito conocer lo que es. En consecuencia, aquí no se parte del concepto de un sujeto que lo sea para sí y que convierta todo lo demás en objetos. ${ }^{17}$

Resolver el problema de la relación entre el ser y la verdad será, según Gadamer, el desafio filosófico principal del pensamiento

\footnotetext{
${ }^{16}$ Como explica Tomás de Aquino, la verdad es una adaequatio per se entre la cosa conocida -en cuanto que ha sido creada por Dios y es conocida por Él- y intelecto divino, mientras que con respecto al intelecto humano es sor El- y e accidens: "La cosa conocida puede estar ordenada a co humano es solamente per accidens. Está ordenada per se al intelecto del que dun intelecto ya sea per se o per se ordena per accidens a cualquier otro del que depende según su ser; en cambio ejemplo, decimos que la casa

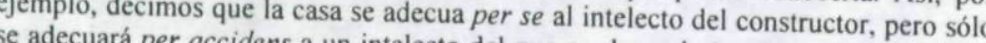
se adecuará per accidens a un intelecto del que no depende (en su ser). Ahora bien, el juicio acerca de la cosa no se apoya sobre aquello que hay en ella per a sino en lo que en ella es per se. De aquí que toda cosa sea en ella per accidens, sentido absoluto, sólo en orden al intelecto del que depende" (S. Th. I, q. 16, a. I c.)
}

contemporáneo. ${ }^{18}$ Para lograrlo, es necesario superar el objetivismo de la concepción cartesiana de la ciencia moderna, disolviendo el dualismo sujeto-objeto que la Modernidad nos ha heredado.

Sin embargo, no es posible volver los pasos atrás y retomar la metafísica clásica, o proseguir el camino del idealismo absoluto. Gadamer ha descartado estas opciones, porque el concepto clásico de verdad como adecuación del intelecto y la cosa descansa sobre un presupuesto de carácter teológico. Por otra parte, tampoco se puede continuar el camino emprendido por la filosofia de la identidad del idealismo alemán: además de ser una forma secularizada de la fundamentación teológica, la completa transparencia del espíritu para sí mismo conduce necesariamente al callejón sin salida de la absolutización del sujeto. Ahora bien, si en el horizonte contemporáneo, demarcado por la finitud y temporalidad del ser, el pensamiento ya no puede recorrer a la metafísica para buscar un fundamento de la adaequatio rei et intellectus, será necesario explorar nuevas vías.

La pregunta es si hay posibilidades finitas de dar razón de esa correspondencia. ¿Se da una fundamentación de dicha correspondencia que no se evada a la infinitud de un espíritu divino y pueda sin embargo explicar la correspondencia ilimitada entre el alma y el ser? Mi respuesta es afirmativa. Hay un camino al que apunta la filosofia cada vez con más claridad y que da testimonio de esa correspondencia. Es el camino del lenguaje. ${ }^{19}$

18 Gadamer expone esta consideración acerca del panorama filosófico contemporáneo en "Die philosophischen Grundlagen des zwanzigsten Jahrhunderts", en Gesammelte Werke, Tubingen: J.C.B. Mohr, 1987, vol. 4, pp. 322.

19 Hans-Georg Gadamer: "La naturaleza de la cosa y el lenguaje de las cosas (1960)" en VM-II, p. 76 (la cursiva es nuestra). Cf. "Subjektivităt und Intersubjektivităt, Subjekt und Person" en Gesammelte Werke..., vol. 10, pp. 93-94. Gianni Vattimo expresa con gran claridad cómo ve Gadamer la situación en que se encuentra la filosofia después del hundimiento del proyecto de la modernidad: "Según Gadamer, el problema de la filosofia contemporánea se define, por lo tanto, como la necesidad de tomarse en serio el concepto hegeliano de espíritu objetivo, teniendo en cuenta al mismo tiempo el descubrimiento existencialista - dicho en sentido más vasto y general posible (desde Kierkegaard hasta Heidegger, pasando por Marx) - del rarácter no-definitivo de la instancia de la conciencia, es decir, del 
Gadamer encuentra en el lenguaje el fundamento de "esa correspondencia que enseñó un día la metafísica como adecuación recíproca de todo lo creado y especialmente como adecuación del alma creada a las cosas creadas"..$^{20} \mathrm{El}$ logos es el "centro en el que se reúnen el yo y el mundo, o mejor, en el que ambos aparecen en su unidad originaria". ${ }^{21}$ En la lingüisticidad, Gadamer ve la forma de experiencia adecuada a nuestra finitud, porque "sólo el centro del lenguaje, por su referencia al todo de cuanto es, puede mediar la esencia histórico-finita del hombre consigo misma y con el

\section{Hombre, mundo y lenguaje}

\subsection{El hombre, animal dialogicum}

Gadamer hace suya la definición clásica del hombre como animal dotado de logos que Aristóteles propone en el libro de la Política ${ }^{23}$ La lingüisticidad (Sprachlichkeit) - como Gadamer llama a esta capacidad del hombre de participar a otros de su interioridad medio del habla - es la diferencia específica que distingue lo humano de lo meramente animal. En efecto,

carácter finito del hombre. Este problema, que los puntos de vista interpretativos de pensamiento posthegeliano no resuelven en modo auténtico, puede entrar en visos de solución, según Gadamer, solamente redescubriendo una tradición de pensamiento que va de Heidegger a Witten aquí junto con toda consolidando en nuestro siglo- la centralidad der a Wittgenstein y ya se va VATTIMO: "L'ontologia ermeneutica...", p. III). 20 "La naturaleza de la cosa..."

última naturaleza de la cosa..." p. 80. Para la metafísica medieval, el fundamento último y garante de la correspondencia entre el alma y las cosas es Dios freador, ha hecho el alma capaz de conocer la verdad, y al mismos Dios creador, que verdaderas las cosas, es decir, adecuadas al creado conocidas por un intelecto creado. Sin al intelecto divino, y capaces de ser fundamentación teológica porque se. Sin embargo, Gadamer no rechaza esta nivel puramente metafision sino que niega a el fundamento último de la verdad Así, ontología gadameriana se configura como un sustituto de la metafísica clásica que no tiene necesidad de apelar a Dios como fundro de decir que en su intención originaria se trata fundamento. En este sentido, se puede 21 VM, p. 567.

${ }^{22} \mathrm{VM}, \mathrm{p} .548$.

${ }^{23}$ Cf. ARistóteles: Política, A 2, 1253a 10. los animales tienen la posibilidad de entenderse entre sí mostrándose recíprocamente lo que les causa placer, para buscarlo, y lo que les produce dolor, para evitarlo para naturaleza no les ha dado más. Sólo los seres humanos poseen, además, el logos que los capacita para informarse mutuamente sobre lo que es útil y lo que es dañino, y también lo que es justo y lo que es injusto. Se trata de un texto de un profundo contenido. El saber lo que es un nocivo no es deseable en sí, sino en referencia a otra cosa que aún no existe, pero le sirve a uno para ejercer su actividad (.) Y Aristóteles aña in es dado también al teles añade inmediatamente que así le injusto... y todo ello, porque entido de lo justo y lo del logos". ${ }^{24}$ elo, porque el hombre es el único poseedor

Gracias a esta capacidad de "hablar" acerca de aquello que todavía no existe, el hombre no sólo se diferencia de aquello que todavía también es libre frente intrínsecamente unida a su entorno. La libertad humana está hombre trascender lo a la lingüisticidad, porque el habla permite al acción en el futuro, para consurar su

Razón, pensamiento, lenguaje y mundo están íntimamente unidos. Para Gadamer, no existe ningún pensamiento o razonamiento que lenguaje es el les decir, independiente del lenguaje, porque "el hombre piensa lenguaje de la razón misma". ${ }^{26}$ Por otra parte, el mundo abierto lingüísticamente" 27 explayarse de los entes en un naturalmente dialógüísticamente". $27 \mathrm{La}$ racionalidad humana es aunque el lenguaje diálogo, ${ }^{28}$ esto no quiere decir que la conversación, es decir, en el contra que se encaden decir que la serie de argumentos en pro y en

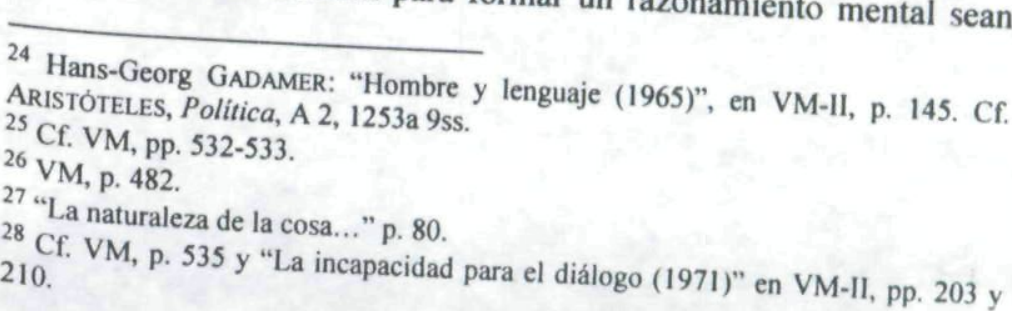


una excepción a la dialogicidad del lenguaje. Como afirma Sócrates en el Teeteto, el pensamiento es el "diálogo del alma consigo misma". ${ }^{29}$ En efecto,

si algo caracteriza a nuestro pensamiento es precisamente este diálogo interminable consigo mismo que nunca lleva a algo definitivo. Esto nos diferencia de ese ideal de un espíritu infinito para el cual todo lo que es y todo lo verdadero aparece en una única intuición. Es nuestra experiencia lingüística, la inserción en este diálogo interno con nosotros mismos, que es a la vez diálogo anticipado con otros y la entrada de otros en diálogo con nosotros, la que abre y ordena el mundo en todos los ámbitos de la experiencia. ${ }^{30}$

Esta concatenación de pensamiento y lenguaje se encuentra en continuidad con la concepción griega del despliegue de la racionalidad, que se expresa con el término logos. ${ }^{31}$

Gadamer ve en el lenguaje no sólo un medio que utiliza la conciencia del sujeto para comunicarse con otros seres semejantes a él, o una especie de potencia espiritual de la que está dotada para sobrevivir, sino el modo de ser específico del hombre. En efecto, en virtud del lenguaje, el hombre

puede pensar y puede hablar. Puede hablar, es decir, hacer patente lo no actual mediante su lenguaje, de forma que también otro lo pueda ver. Puede comunicar todo lo que piensa; y lo que es más, gracias a esa capacidad de comunicarse las personas pueden pensar lo común, tener conceptos comunes, sobre todo aquellos conceptos que posibilitan la convivencia de los hombres sin asesinatos ni homicidios, en forma de vida social, de una constitución política, de una vida económica articulada en la división del

29 PLATÓN: Teeteto, 189e-190a. Gadamer hace frecuentes referencias a este pasaje de los diálogos platónicos. Cf. p. ej. VM-II, pp. 151, 181, 195-197.

30 “¿Hasta qué punto el lenguaje preforma el pensamiento?" en VM-II, p. 196.

31 Cf. Antonio DA RE: L ermeneutica di Gadamer e la filosofia pratica, Rimini: Maggioli, 1982, pp. 130-131. trabajo. Todo esto va implícito en el simple enunciado de que el hombre es el ser vivo dotado de lenguaje. ${ }^{32}$

\subsection{Tener lenguaje es "tener" mundo}

Como sucede con todos los conceptos fundamentales, resulta difícil definir la noción de mundo. Sobre sus exactos contornos nulta pondrán jamás de acuerdo dos filósofos. El mundo es mucho más que el lugar en el que se "da" ese ente que llamamos hombre, pues posee un sentido de totalidad que enmarca el ser de todo aquello que es. La realidad - aún siendo la misma que experimenta el resto de cualquier otra creatura constituye por medio de porque para el hombre el mundo se mundo. A su ex logos no existe el del mundo. Para Gadamer en la manifestación respecto del otro, porque

(...) el lenguaje no afirma a su vez una existencia autónoma es mundo en cuanto habla a través de él. No sólo el mundo tiene su verdadera que accede al lenguaje: el lenguaje sólo representa el mundo significa, pues, al ma humanidad originaria del lenguaje del estar-en-el-mundo del tiempo la lingüisticidad originaria

Aprender a hablar significa adquirir familiaridad con el mundo, es decir, conocerlo tal y como nos sale al encuentro. ${ }^{34} \mathrm{Al}$ hablar del mundo unos con otros, el mundo se convierte en el punto de mundo es el de unión de todos los hombres entre sí, porque "el todos, que puede decir que, "para los que hablan entre si". ${ }^{35}$ Por eso Gadamer una forma bajo "a está ahí como mundo, en puesto en él. Y esta existencia del para ningún otro ser vivo del mundo está constituida

${ }^{32}$ "Hombre y lenguaje (1965)", en VM-II, p. 145.

${ }^{34} \mathrm{Cf}$. ".

${ }^{35}$ VM 
lingüísticamente" ${ }^{36}$ En este proceso de conformación lingüística del mundo, el lenguaje y la libertad se encuentran intrínsecamente unidos. En efecto, para Gadamer,

lo uno forma parte de lo otro y a la inversa. Elevarse por encima de las coerciones de lo que le sale a uno al encuentro desde el mundo significa tener lenguaje y tener mundo. (...) la elevación o el estar elevado por encima de las coerciones del mundo es algo que se da siempre allí donde hay lenguaje $\mathrm{y}$ allí donde hay hombres. ${ }^{37}$

Pero tener mundo significa también poder disponer de él. El primer acto de disposición de las cosas que el hombre lleva a cabo es el hecho de ponerles un nombre. Al adquirir un nombre, las cosas dejan de sernos extrañas: al nombrarlas, el hombre se las apropia. Así, a través de esta actividad exquisitamente lingüística, el hombre también ejerce su libertad, porque "esta libertad frente al entorno es también libertad frente a los nombres que damos a las cosas, como expresa también esa profunda narración del Génesis según la cual Adán recibió de Dios la potestad de poner nombres". ${ }^{38}$

\subsection{Absolutización de la experiencia lingüística}

En el horizonte del lenguaje se estructura toda la existencia humana: la vida social y política, las relaciones económicas y laborales, etc. No existe para Gadamer ninguna experiencia del hombre que se pueda constituir en un ámbito extra-lingüístico. ${ }^{39}$

36 VM, p. 531

${ }^{37}$ VM, p. 532 . Cf. p. 543

38 VM, p. 532. Cf. Gen. 2, 20.

39 Jürgen Habermas critica la absoluta lingüisticidad de la experiencia propuesta por Gadamer. Para él, experiencias como el poder y el trabajo poseen un carácter nolingüístico. Al inicio de los años setenta hubo una intensa discusión entre los dos en torno a este problema. Cf. Jürgen HABERMAS: "Der Universalitătanspruch der Hermeneutik", en R. BUBNER, K. CRAMER, R. WIEHL (eds.): Hermeneutik und Dialektik. Festschrift für H.-G. Gadamer, Tübingen: J.C.B. Mohr, 1970, vol. I, pp. 73-104; Hans-Georg GaDAmER: "Hasta qué punto el lenguaje preforma el pensamiento (1973)", "La universalidad del problema hermenéutico (1966)" y "Réplica a Hermenéutica y crítica de la ideologia (1971)" en VM-II, pp. 195-201, 213-224 y 243-265 respectivamente.
También las experiencias de la temporalidad y del pasado se encuentran mediadas lingüísticamente. La experiencia histórica, como diálogo de cada hombre con la tradición a la que pertenece, es lenguaje. ${ }^{40} \mathrm{De}$ esta manera, la realidad se nos revela como un "tejido que los hombres, en su convivencia o interacción dialógica, van poco a poco tramando. (...) El diálogo que vamos entretejiendo - y en el que desde que empezamos estamos sumidos- es la realidad del mundo como texto creado por sus intérpretes". ${ }^{41}$

Así, el lenguaje ha asumido en el pensamiento gadameriano connotaciones que van más allá de la mera descripción fenomenológica del mismo, convirtiéndose en la estructura universal-ontológica que enmarca por entero la vida del hombre y que le permite acceder a todo lo que puede ser conocido comprendido.

La lingüisticidad de nuestra experiencia del mundo precede a todo cuanto puede ser reconocido e interpretado como ente. La relación fundamental de lenguaje y mundo no significa por lo tanto que el mundo se haga objeto del lenguaje. Lo que es objeto del conocimiento y de sus enunciados se encuentra por el contrario abarcado siempre por el horizonte del mundo del lenguaje. La lingüisticidad de la experiencia humana del mundo no entraña la objetivación del mundo. ${ }^{42}$

El mundo no está más allá del lenguaje, porque más allá no hay nada. No existe un "mundo en sí" externo a toda lingüisticidad, pues

toda acepción del mundo se refiere al ser en sí de éste. Él es el todo al que se refiere la experiencia esquematizada lingüisticamente. La multiplicidad de tales acepciones de mundo no significa relativización del 'mundo'. Al contrario,

\footnotetext{
40 “. (...) la tradición no es un simple acontecer que pudiera conocerse y dominarse por la experiencia, sino que es lenguaje, esto es, habla por si misma como lo hace un tú" (VM, p. 434. Cf. p. 468)

Hermenédo INCIARTE: "Hermenéutica y sistemas filosóficos" en AA.VV., Biblia y Hermenéutica, Pamplona: EUNSA, 1986, p. 93

${ }^{42}$ VM, p. 539.
} 
lo que el mundo es no es nada distinto de las acepciones en las que se ofrece. . $^{3}$

En el lenguaje, la autoconciencia y el saber acerca del mundo encuentran su fundamento último e insuperable. En efecto,

cuando el lenguaje se explicita como tal, aparece como la mediación primaria para el acceso al mundo. Así se clarifica el carácter irrebasable del esquema lingüístico del mundo. El mito de la autocerteza, que en su forma apodíctica pasó a ser el origen y la justificación de toda validez, y el ideal de fundamentación última que se disputan el apriorismo y el empirismo, pierde su credibilidad ante la prioridad e ineludibilidad del sistema del lenguaje que articulad ineludibilidad del sistema del lenguaje que articula toda conciencia $y$ todo saber. (...) El mundo intermedio del lenguaje aparece frente a las ilusiones de la autoconciencia y frente a la ingenuidad de un concepto positivista de los hechos como la verdadera dimensión de la realidad. ${ }^{44}$

\subsection{El juego del lenguaje}

En la ontología gadameriana, el lenguaje se configura, por lo tanto, como el único medio a través del cual se da o manifiesta la totalidad: el sujeto y sus objetos, el hombre y el mundo. El logos es la instancia última, el punto de referencia absoluto que nos permite situarnos en el mundo, en fin, "la verdadera huella de nuestra finitud. Siempre nos sobrepasa". Por esta razón, "la conciencia del individuo no es el criterio para calibrar su ser", 45 porque no existe "ninguna conciencia individual en la que exista el lenguaje que ella habla" ${ }^{46}$

${ }^{43}$ VM, p. 536. Gadamer rechaza como teológica -o en su caso, diabólica - la tentación de hablar del "ser en si" del mundo: "El que pretenda diabólica- la "acepciones" el "ser en sí" tendrá que pensar o teológicamente en sí ya no es para él sino para Dios-o diabólicamente, en calidad entonces el ser que pretende demostrarse a si mismo su o diabólicamente, en calidad de individuo entero debe obedecerle - y entonces el ser en sí del haciendo ver que el mundo restricción de la omnipoten en sí del mundo será para él una

44 "Texto e interpretación...,", p. 327.

45 "Hombre y lenguaje...", p. 149.

46 "Hombre y lenguaje...,", p. 149.
En efecto, el lenguaje no puede ser considerado un "diseño de una conciencia individual ni de un espíritu colectivo", 47 como es eì caso del espíritu absoluto del idealismo hegeliano. Tampoco el logos es "un diseño previo al mundo que es producto de la subjetividad", ${ }^{48} \mathrm{ni}$ un sujeto - en el sentido moderno de la palabra-, dado que, si el lenguaje es fundamento de toda conciencia, no puede ser en si mismo auto-conciencia. En este sentido, al logos le es esencial más bien la "inconsciencia", es decir, el olvido de sí, porque "cuanto más vivo es un acto lingüístico es menos consciente de sí mismo". ${ }^{49}$ Es experiencia común para el autor de Verdad $y$ método que la conversación o el diálogo auténticos absorban a todos los que participan en ella, dejando la conciencia del yo individual en un segundo plano, detrás del tema u objeto del que se está hablando. En este sentido,

el habla no pertenece a la esfera del yo, sino a la esfera del nosotros. (...) Porque la realidad espiritual del lenguaje es pneuma, la del espíritu que unifica el yo y el tú. La realidad del habla, como se ha observado desde hace tiempo, consiste en el diálogo. Pero en el diálogo impera siempre un espíritu, espíritu de comunicación y de intercambio fluido entre el yo y el tú. ${ }^{50}$

Para explicar la naturaleza de este espíritu, Gadamer acude a nuestra experiencia del juego. ${ }^{51}$ Cualquiera que haya jugado un partido de fútbol, baloncesto o tenis, o a las cartas, sabe que para hacerlo bien hay que "meterse" en el juego, centrando la atención en lo que se está jugando. Jugar es siempre jugar a algo, que está ya predeterminado antes de que los jugadores tomen parte en el juego. "Cada juego plantea una tarea particular al hombre que lo juega". 52 El hombre es libre de jugarlo o no, pero una vez dentro del juego, tiene que respetar el conjunto de reglas que lo determinan, porque si

\footnotetext{
47 "La naturaleza de la cosa...", p. 79.

48 "La naturaleza de la cosa...", p. 79.

49 "Hombre y lenguaje...", pp. 149-150.

50 "Hombre y lenguaje...,", p. 150

51 Gadamer dedica en Verdad y método el apartado "El juego como hilo conducto de la explicación ontológica" a desarrollar esta idea. Cf. VM, pp. 143-154.
} 
no, el juego se destruye. Hay que dejarse llevar por la dinámica de lo jugado. Por el contrario, si alguno de los jugadores se distrae, en ese mismo instante se está saliendo del juego. En efecto, no hay nada más desesperante que jugar con o contra una persona que no se toma el juego en serio.

Para Gadamer, la conciencia actual que tienen los jugadores no es una característica necesaria del juego. No son ellos los protagonistas del juego. Más bien, "todo jugar es ser jugado. La atracción del juego, la fascinación que ejerce, consiste precisamente en que el juego se hace dueño de los jugadores". ${ }^{53}$ En el fondo, "el sujeto del juego no son los jugadores, sino que a través de ellos el juego simplemente accede a su manifestación".54. Por esta razón, el término juego posee un carácter impersonal, que permite que sea aplicado también al movimiento armónico de entidades inanimadas, como cuando se habla de "juego de luces", "el juego de las olas", etc. 55

El lenguaje no es un juego en sentido estricto - se trata de la realidad última que engloba en sí todos los juegos-, pero para Gadamer resulta esclarecedor el parangón, pues "la naturaleza del juego (...) es estructuralmente afin a la naturaleza del diálogo, que es el lenguaje realizado". ${ }^{56}$ Para Gadamer, "el lenguaje (...) es el juego en el que todos participamos. Nadie es antes que los otros. Cada cual está 'en ello' y es 'mano' en el juego".57 Al entrar en una conversación —en modo similar a los participantes en un juegolos interlocutores desaparecen en el hacerse del lenguaje por medio del diálogo:

las palabras que encontramos atrapan en cierto modo nuestro pensamiento y lo integran en unas relaciones que sobrepasan la instantaneidad de ese pensamiento. (...) La vida del

\footnotetext{
53 VM, p. 149.

54 VM, p. 145

$55 \mathrm{VM}$, pp. 148-149.

56 “Hombre y lenguaje...", p. 150.

57."Retórica, hermenéutica y crítica de la ideología. Comentarios metacriticos a Verdad y método I (1967)", en VM-II, p. 235.
}

lenguaje consiste en la continuación ininterrumpida del juego que empezamos cuando aprendimos a hablar. ${ }^{58}$

Así, no somos nosotros los que "llevamos" una conversación, sino que, más bien, somos "llevados" por ella. ${ }^{59}$ Por eso, del mismo modo que el juego se apodera de los jugadores, convirtiéndolos en "piezas del juego", nosotros no hablamos el lenguaje, sino que el lenguaje "nos" habla.

\section{Consideraciones conclusivas}

Durante la exposición de la ontología hermenéutica gadameriana que hemos llevado a cabo en las páginas precedentes, hemos querido evitar comentarios y observaciones que pudiesen oscurecer el hilo del discurso. Sin embargo, no queremos terminar estas páginas sin hacer un balance final y algunas observaciones críticas.

La certeza de la conciencia como piedra de toque del conocimiento verdadero (el cogito cartesiano) acabó haciendo de la autoconciencia el origen último de la verdad, capaz de garantizar por sí sola el avance del saber y del progreso humanos. Sin embargo, la experiencia viva de la finitud y temporalidad que impregna actualmente buena parte de la cultura occidental, ha sustituido las certezas de la Modernidad. Las guerras mundiales y los horrores de las ideologías totalitarias del siglo $\mathrm{XX}$ provocaron el hundimiento del mito del continuo progreso en todos los campos, y la desconfianza en los poderes ilimitados de la razón humana. Para muchos, la pretensión de poseer la verdad es algo utópico, y la experiencia reciente nos muestra que las utopías han creado monstruos. Ante esta crisis de la verdad, Gadamer ve con gran lucidez la necesidad de apoyarla en algo que esté más allá del dualismo sujeto-objeto que nos ha heredado la gnoseología moderna. Porque, si la razón humana no es el origen del ser de las cosas que conoce, tampoco puede garantizar ni certificar su verdad. Por unir en sí finitud e infinitud, Gadamer coloca el lenguaje como fundamento

\footnotetext{
58 "Sobre la problemática de la autocomprensión. Una contribución hermenéutica a tema de la 'desmitologización' (1961)", en VM-II, p. 130.
} 
o realidad última en cuyo seno se lleva a cabo la "adecuación del intelecto y la cosa".

Gadamer modela su concepto de lenguaje inspirándose en el concepto de espíritu desarrollado por la tradición de los místicos cristianos - sobre todo la que se remonta a Thauler, con sus venaturas panteístas- y que Hegel había hecho suyo.

Este concepto de espíritu, que trasciende la subjetividad del yo, encuentra su verdadera correspondencia en el fenómeno del lenguaje, que poco a poco se ha ido colocando al centro de la filosofia contemporánea. Y esto es así, porque el fenómeno del lenguaje, en comparación con ese concepto de espíritu que Hegel tomó de la tradición cristiana, posee la ventaja - adecuada a nuestra finitud- de ser infinito como el espiritu y sin embargo finito como todo evento que sucede en el tiempo y el espacio. ${ }^{60}$

De esta manera, en esta búsqueda del fundamento ontológico de la experiencia de la verdad, Gadamer ha hecho suyo el "mal infinito" que tanto había denostado Hegel, pues el lenguaje es espíritu infinito, pero que no vuelve a sí mismo: es irreflexivo, y por lo tanto, inconsciente. En efecto, esta línea de pensamiento es una evolución del proyecto filosófico hegeliano, pero siguiendo - bajo el influjo de su maestro Martin Heidegger- el camino trazado por el historicismo de Wilhelm Dilthey, que rechaza la grande síntesis del espíritu absoluto, desarrollando en cambio la esfera del espíritu objetivo. El infinito hacerse del lenguaje que Gadamer postula no culmina en la perfecta y eterna autorreflexión del espíritu del idealismo hegeliano, ya que se trata de una "conversación" que no termina jamás. El diálogo está siempre abierto:

la capacidad de dicción avanza incansablemente con la universalidad de la razón. Por eso el diálogo posee siempre una infinitud interna y no acaba nunca. El diálogo se interrumpe, bien sea porque los interlocutores han dicho bastante o porque no hay nada más que decir. Pero esa

60 Hans-Georg GADAMER: "Die philosophischen Grundlagen des zwanzigsten Jahrhunderts", en Gesammelte Werke, Tübingen: J.C.B. Mohr, 1987, vol. 4, p. 21. interrupción guarda una referencia interna a la reanudación del diálogo. ${ }^{61}$

De este modo, sin volver a la fundamentación trascendente que propone la metafísica clásica, Gadamer trata de evitar las aporías del espíritu absoluto hegeliano y del objetivismo de la gnoseología positivista.

Si bien la crítica gadameriana de los límites del subjetivismo moderno y de los excesos de la Modernidad es acertada, nos parece que la solución que propone para salir del callejón en el que ha terminado la filosofia post-cartesiana no logra su cometido, debido a los límites intrínsecos de su punto de partida. Ya desde el principio, el ámbito en el que la ontología de Gadamer se mueve es parcial: el horizonte de la problemática gnoseológica de la Modernidad, que soslaya la multiplicidad del ser, reduciéndolo al ens ut verum. En este caso concreto, si no existe experiencia humana que pueda evadirse de las redes de la lingüisticidad, no es posible "hablar" de un ser extra-lingüístico. Gadamer cierra las puertas a la consideración del ens ut esse, es decir, a toda experiencia de verdad que trascienda los límites de la experiencia mediada lingüísticamente (esse ut logos). En pocas palabras, nos parece que es esto y no otra cosa lo que significa la enigmática frase gadameriana "el ser que puede ser comprendido es lenguaje" (Sein, das verstehen werden kann, ist Sprache). ${ }^{62}$

Por otra parte, esta absolutización del logos paradójicamente acaba sustituyendo el espíritu absoluto hegeliano - autoconciencia y reflexión absolutas- por otro absoluto pero con características diversas: un espíritu no-reflexivo, es decir, no-subjetivo. Como señala Antonio Da Re,

Gadamer, preocupado por el peligro de recaer en la metafísica y en la infinitud, tareas demasiado arduas para la limitación humana, se queda atrapado en la consideración de la sola finitud humana, de la sola historicidad. Pero, de tal

\footnotetext{
61 "Hombre y lenguaje...,", p. 151

${ }^{62}$ VM, p. 567.
} 
manera que, lo que a sus ojos se presentaba como relativo y contingente, por el sólo hecho de que solamente tematiza eso, se convierte al final en el "absoluto". En Gadamer se da la absolutización de lo finito, de la contingencia. ${ }^{63}$

Al final, Gadamer no consigue superar el inmanentismo de la metafísica idealista. Al quedarse en el plano de la historicidad del espíritu objetivo, la ontología gadameriana termina en una absolutización de una verdad parcial - la experiencia humana de la temporalidad y de la finitud-que mutila la integridad del ser. En el fondo, la afirmación del lenguaje como realidad última es sólo un nuevo avatar del vitalismo historicista. Porque Gadamer niega al hombre la posibilidad de trascender la finitud de su experiencia mundana. Obviamente, este hecho tiene graves consecuencias a nivel antropológico: el ser del hombre y de su mundo vital se disuelven en la historia infinita del continuo hacerse del logos. No hay un ser "propio" del hombre: éste es sólo la sede en la que el logos se manifiesta. Usando la metáfora gadameriana, el lenguaje juega con nosotros. La libertad que Gadamer ha reconocido al hombre como expresión de la intrínseca lingüisticidad de su ser, se vanifica en una mera apariencia. En definitiva, si el hombre no "es" algo realmente distinto del logos, tampoco puede ser sujeto libre y responsable de sus actos.

${ }^{63}$ A. DA RE: L'ermeneutica di Gadamer..., p. 128.

\section{El sentido común en Saul Kripke como método}

Carlos López Zaragoza Universidad del Valle de Atemajac

\section{A Alice}

This paper intends to show that the main goals of Saul Kripke's theory of reference hang on the methodological usage of common sense, taking common sense as the natural way in which intelligence approach to reality and which is reflected in natural or ordinary language. The key to bring to light Kripke's ideas about common sense is analyzing the texts in which he talks about 'intuition'.

En las páginas finales de El compromiso esencialista de la lógica modal. Un estudio de Quine y Kripke, Jaime Nubiola concluye que Kripke ha recuperado algunas tesis de la metafisica realista gracias a la "extraordinaria valoración de la intuición prefilosófica", de la "palmaria y sencilla intuición acerca del mundo y de las cosas, en la que la filosofia ha tenido sus orígenes".' Por este motivo, adaptando la etiqueta que se ha dado a la filosofía oxoniense, Nubiola propone llamar a Kripke "filósefo del pensamiento ordinario".?

Este modo de referirse a Saul Kripke pone de relieve el método empleado por él. Kripke bien puede ser considerado un filósofo del sentido común, entendiendo esta expresión —sentido común- tal como aparece en el lenguaje ordinario, es decir como el modo de juzgar y conocer espontáneo de cualquier hombre. El sentido común,

I Jaime NuBiola: El compromiso esencialista de la lógica modal, Pamplona: EUNSA, 1984, p. 311

2 J. NuBIOLA: El compromiso..., p. 312. 
Copyright of Tópicos. Revista de Filosofía is the property of Universidad Panamericana and its content may not be copied or emailed to multiple sites or posted to a listserv without the copyright holder's express written permission. However, users may print, download, or email articles for individual use. 